\title{
Analysis of Readability Discourse Level and Authenticity of "Sahabatku Indonesia" for BIPA Level C1 Textbook by Indonesia's Language Agency Based on the Fry Chart
}

\author{
Rishe Purnama Dewi ${ }^{1}$, R. Kunjana Rahardi², \\ Yuliana Setyaningsih ${ }^{3}$, Septina Krismawati ${ }^{4}$ \\ Sanata Dharma University, Yogyakarta, Indonesia \\ budimanrishe@usd.ac.id; budimanrishe78@gmail.com
}

\begin{abstract}
One of the requirements for a good textbook is to have the adequate readability discourse level. BIPA Textbook published by Indonesia's Language Agency needs to be investigated whether it has good readability level. Therefore, this study aims to measure the readability discourse level in the BIPA textbook which is considered to have one of discourse readability requirements. In addition, this study also examines the authenticity of the discourse of the book. The researchers asses the level of readability using the Fry chart and authenticity study for the analysis of each discourse. This research belongs to quantitative descriptive research. The data source of this research is the whole discourse contained in the Sahabatku Indonesia book published by Indonesia's Language Agency for level $\mathrm{C} 1$. The research results using the chart Fry found that five discourses are appropriate for the learning in level C1 BIPA with the category of "need instructional or guidance of the teacher". Related to the level of discourse authenticity, the researchers found three discourse with high authenticity.
\end{abstract}

Keywords: readability, readability level, the Fry chart, discourse, authenticity.

\section{PENDAHULUAN}

Materi pembelajaran yang baik perlu memenuhi syarat tertentu. Terlebih lagi materi yang berbentuk buku ajar. Buku ajar atau buku teks menjadi elemen universal dalam pembelajaran yang dapat menjadi sarana politik maupun pengenalan budaya kepada pembelajar [1]. Karena itu, peran buku teks menjadi penting dalam pembelajaran mengingat buku teks menjadi jembatan dalam membentuk pengetahuan dan pemahaman pembelajar, khususnya pembelajar bahasa asing. Salah satu syarat buku yang baik adalah membentuk pengetahuan adalah buku harus mengandung tiga domain utama mulai dari domain pengetahuan, psikomotor, dan afektif [2]. Oleh karena itu, penyediaan bahan ajar termasuk wacana pendukung dalam buku teks hendaknya memenuhi persyaratan yang memadai guna mengembangkan kemampuan berbahasa pembelajarnya.

Buku teks Bahasa Indonesia dalam konteks BIPA memiliki peranan penting. Wacana dalam buku teks BIPA untuk setiap jenjang haruslah memenuhi kriteria yang tepat. Salah satu cara menilai apakah wacana yang terdapat dalam buku teks BIPA untuk level tertentu telah memadai 
adalah penggunaan uji keterbacaan teks dengan berbagai formula. Salah satu formula yang dapat dipakai menguji tingkat keterbacaan teks adalah grafik Fry. Penggunaan formula dalam penelitian ini masih terbatas meski dapat dipahami bahwa perhitungan keterbacaan dengan formula belum dapat memaksimalkan hasil keterbacaan khususnya dalam menjawab permasalahan apa yang membuat teks mudah atau sukar dibaca. Namun demikian, pengujian dengan salah satu rumus setidaknya membantu penafsiran keterbacaan wacana dalam buku teks [3].

Pendapat Widharyanto, dkk. [4] mengatakan bahwa salah satu kelebihan penggunaan alat uji keterbacaan grafik Fry adalah penentuan keterbacaan dengan alat uji keterbacaan relatif mudah dipergunakan. Selain itu, pengadministrasian hasil uji pun lebih mudah. Terkait dengan hasil uji keterbacaan grafik Fry, gambaran hasil uji keterbacaan pun mampu memberikan gambaran yang lebih baik. Dengan kata lain, hasil penentuan uji keterbacaan memiliki korelasi yang lebih tinggi dibandingkan dengan alat uji keterbacaan lainnya dan penafsiran uji keterbacaan ini lebih dapat dipertanggungjawabkan mengingat langkah-langkah perhitungan yang jelas khususnya perhitungan kata dan suku kata dalam wacananya. Alasan-alasan tersebutlah yang menjadi dasar penggunaan grafik Fry sebagai alat uji keterbacaan buku teks dalam penelitian ini. Dengan demikian, ketedasan dalam hal ini kepahaman kebahasaan dan kejelajahan yang berkaitan denga tata huruf dapat menentukan tingkat keterbacaan buku teks [5].

Selain grafik Fry, penelitian ini menentukan kualitas wacana buku teks ditinjau dari autentisitasnya. Autentisitas yang dimaksud sesuai dengan paparan [6] yang menyatakan bahwa autensitas diperlukan untuk pembelajaran bahasa kedua atau bahasa asing. Autensitas diperlukan dalam pembelajaran BIPA guna memberikan gambaran bahwa teks atau wacana yang dipilih dapat menggambarkan interaksi pembelajaran secara kontektual sehingga dan bermakna bagi pembelajarnya dan diarahkan pada kealamiahan. Alamiah dimaksudkan bahwa pembelajaran tidak didasarkan pada kepura-puraan tetapi konteks sosial dalam wacana sungguh terdapat dalam situasi komunikasi nyata. Sebagai contoh teks tawar-menawar yang disajikan dalam buku ajar BIPA sebaiknya mengambil konteks nyata berupa negosiasi yang terjadi di ranah jual beli seperti pasar tradisional. Karena itu, autensitas menjadi dasar penelitian ini.

Autensitas dan uji keterbacaan grafik Fry inilah yang menjadi fokus untuk menilai tingkat keterbacaan teks-teks yang terdapat dalam buku Sahabatku Indonesia terbitan Badan Bahasa. Hasil uji keterbacaan dan pembahasan uraian autentisitas teks dapat dikorelasi khususnya untuk pembelajaran bahasa kedua atau bahasa asing [7]. Alasan utama buku ini dipilih untuk diteliti keterbacaan dan autensitas teksnya adalah buku Sahabatku Indonesia menjadi buku pegangan di berbagai lembaga kursus BIPA. Lebih dari itu, beberapa instansi termasuk KBRI yang memiliki kelas-kelas BIPA menggunakan buku ini sebagai pegangan wajib untuk pembelajaran BIPA. Kajian terhadap keterbacaan wacana buku ini diharapkan mampu memberi masukan terkait kualitas teks atau kelayakan teks sehingga pengguna baik pengajar dan pembelajar dapat menggunakan dan mempelajari teks ini dengan maksimal. Apabila teks kurang memenuhi syarat, pengajar BIPA dapat melengkapinya dengan teks pendukung lainnya sehingga pembelajar dapat memaknai konteks isi teks dan mempelajarinya dengan baik.

Buku teks BIPA level atau tingkat $\mathrm{C} 1$ dipilih dengan sejumlah rasionalisasi. Pertama, pembelajar level ini sudah memiliki kemahiran berbahasa yang lebih baik. Kedua, pembelajar sudah memiliki kemampuan memahami berbagai jenis tulisan yang panjang dan menantang, berjangkauan luas. Ketiga, pembelajar sudah mampu mengenali makna eksplisit yang terkandung dalam tulisan. Oleh karena itu, penelitian ini berfokus pada pengkajian keterbacaan teks dan autensitas wacana buku teks Sahabatku Indonesia level C1 dengan maksud menilai kualitas wacana dan memberi masukan kepada pengajar atau pengguna buku terkait hasil kajian 
penelitian ini. Dengan demikian, penggunaan buku tersebut akan jauh lebih maksimal pemanfaatannya di kelas-kelas BIPA level C1.

\section{METODE PENELITIAN}

Penelitian ini termasuk dalam jenis penelitian deskriptif. Populasi penelitian ini adalah seluruh wacana yang memenuhi syarat perhitungan grafik Fry dan ketentuan autensitas teks. Terdapat dua belas wacana yang memenuhi syarat grafik Fry dan penentuan autensitas. Sumber data penelitian buku terbitan Badan Bahasa ini adalah kedua belas teks yang terdapat dalam buku "Sahabatku Indonesia" terbitan Badan Bahasa untuk Level C1. Instrument dalam penelitian ini adalah peneliti sendiri yang secara penuh melaksanakan kajian analisis keterbacaan teks. Hal ini sangat sesuai dengan pendapat [8] yang memaparkan bahwa intrumen penelitian dapat dilakukan oleh peneliti sendiri. Hal ini disebabkan oleh peneliti yang melakukan perencanaan, peneliti menjadi pelaksana pengumpulan data, melakukan analisis, penafsir data, dan pada akhirnya menjadi pelapor hasil penelitian yang diteliti. Selain itu, peneliti pun memiliki pengetahuan yang cukup terkait kajian keterbacaan dan autentifikasi buku teks.

Teknik pengumpulan data penelitian ini meliputi tiga tahapan. Pertama, peneliti melakukan teknik baca dengan cara dengan melihat buku dan memahami isi bacaan untuk setiap teks yang terdapat pada buku Sahabatku Indonesia level C1. Kedua, peneliti mengukur tingkat keterbacaan menggunakan formula grafik Fry dengan menghitung jumlah kata dan suku kata sesuai ketentuan grafik Fry. Selain itu, peneliti menentukan tingkat keterbacaan teks dengan grafik Fry, peneliti juga menentukan tingkat autentisitas buku teks Sahabatku Indonesia dengan cara menentukan sumber teks yang dipergunakan dalam buku tersebut secara akurat sesuai dengan fakta dan tidak direkayasa. Langkah selanjutnya, peneliti melakukan teknik catat dengan cara menyusun hasil penjumlahan data-data numerik hasil perhitungan grafik Fry dan autensitas teks yang telah diperoleh ke dalam tabel tabulasi.

Proses pengumpulan data untuk analisis setiap wacana dilakukan dengan cara memberi tanda pada setiap wacana yang terdapat dalam buku teks tersebut. Selanjutnya, dilakukan perhitungan pada jumlah kata, jumlah kalimat, dan juga jumlah suku kata untuk mengukur tingkat keterbacaan berdasarkan grafik Fry. Hal ini dilakukan dengan tujuan agar tidak terjadi kesalahan dalam perhitungan.

Teknik analisis data kuantitatif dipergunakan dalam penelitian ini. Hal ini dilakukan dengan alasan data penelitian ini berupa data angka yang dijumlahkan sebagai data keterbacaan yang kemudian dianalisis. Adapun urutan atau tahapan analisis data penelitian ini adalah (1) menentukan wacana atau teks yang dijadikan objek penelitian yaitu buku teks "Sahabatku Indonesia" terbitan Badan Bahasa untuk Level C1, (2) menentukan hasil penjumlahan data-data numerik perhitungan teks dengan formula keterbacaan grafik Fry, (3) mendeskripsikan hasil temuan berupa tingkat keterbacaan dalam buku teks Sahabatku Indonesia terbitan Badan Bahasa untuk Level C1 berdasarkan grafik Fry, (4) menentukan tingkat autentisitas wacana buku teks Sahabatku Indonesia berdasarkan syarat-syarat autentik, dan (5) menarik simpulan dari hasil temuan.

\section{HASIL DAN PEMBAHASAN}

Hasil temuan diperoleh data sebagai berikut. Adapun wacana dalam buku teks "Sahabatku Indonesia" terbitan Badan Bahasa level C1 berjumlah dua belas wacana. Berdasarkan langkahlangkah perhitungan grafik Fry, perhitungan kesukaran kata dan kerumitan gramatikal menjadi 
hal yang dilakukan dalam perhitungan. Hal ini sejalan dengan konsep perhitungan keterbacaan Fry [9]. Berdasarkan hasil temuan diperoleh lima wacana yang sesuai untuk pembelajar BIPA level C1. Kelima wacana tersebut berjudul Danau Toba, Hubungan Lingkungan Hidup dengan Pembangunan, Ulasan Film: The Little Prince (20150, Mitos Seputar Gerhana Matahari di Indonesia, dan Alzheimer. Berikut ini tabel data kesesuaian tingkat keterbacaan kelima teks tersebut.

Tabel 1 Tingkat Keterbacaan Teks yang sesuai dengan Grafik Fry

\begin{tabular}{clcccc}
\hline $\begin{array}{c}\text { Kode } \\
\text { Teks }\end{array}$ & \multicolumn{1}{c}{ Judul Wacana } & $\begin{array}{c}\text { Jumlah } \\
\text { Kalimat }\end{array}$ & $\begin{array}{c}\text { Jumlah } \\
\text { Suku Kata }\end{array}$ & Penafsiran & Keterangan \\
\hline Teks 1 & Danau Toba & 6,6 & 156 & $9, \mathbf{1 0}, 11$ & Sesuai \\
\hline Teks 5 & $\begin{array}{l}\text { Hubungan } \\
\text { Lingkungan Hidup } \\
\text { dengan } \\
\text { Pembangunan }\end{array}$ & 5,3 & 164 & $11, \mathbf{1 2}, 13$ & Sesuai \\
\hline Teks 8 & $\begin{array}{l}\text { Ulasan Film: The } \\
\text { Little Prince (2015) }\end{array}$ & 2,9 & 139 & $9, \mathbf{1 0}, 11$ & Sesuai \\
\hline Teks 10 & $\begin{array}{l}\text { Mitos Seputar } \\
\text { Gerhana Matahari di } \\
\text { Indonesia }\end{array}$ & 6,9 & 157 & $9, \mathbf{1 0}, 11$ & Sesuai \\
\hline Teks 11 & Alzheimer & 4,9 & 164 & $11, \mathbf{1 2}, 13$ & Sesuai \\
\hline
\end{tabular}

Kelima teks tersebut sesuai karena titik temu antara panjang kata dan panjang kalimat berada pada daerah yang sesuai dengan daerah penafsiran. Salah satu bukti perhitungan pada teks berjudul Danau Toba. Kata ke-100 pada wacana tersebut berada pada kata ke-13 dari 22 kata. Dengan demikian, perhitungan kalimat menjadi tidak utuh dan perhitungan tersebut adalah 13 : $22=0,59$ dibulatkan menjadi 0,6. Kemudian, hasil perhitungan tersebut dijumlahkan secara keseluruhan sehingga diperoleh $6+0,6=6,6$. Dapat disimpulkan bahwa hasil perhitungan kalimat utuh menjadi 6,6. Untuk perhitungan suku kata, hasil perhitungan keseluruhan suku kata dikalikan rumus grafik Fry sebesar 0,6. Perhitungan suku kata wacana ini Danau Toba adalah $260 \times 0,6=156$. Dari perhitungan kata, sukukata, dan kerumitan kalimat, diperoleh hasil perhitungan sebesar 6,6 dan 156. Hasil tersebut dimasukkan ke dalam Grafik Fry sehingga titik temu kedua unsur tersebut jatuh pada tingkat pembaca 10. Mengacu pada teori grafik Fry, peringkat kelas pembaca ini dikurangi satu tingkat dan ditambah satu tingkat. Hasil yang diperoleh adalah $10-1=9$ dan $10+1=11$. Untuk itu, wacana kode teks 1 berada pada tingkat pembaca 9, 10, dan 11 tergolong sesuai untuk pembelajar level $\mathrm{C} 1$. Berikut ini gambar titik temu pada Grafik Fry hasil perhitungan teks Danau Toba. 


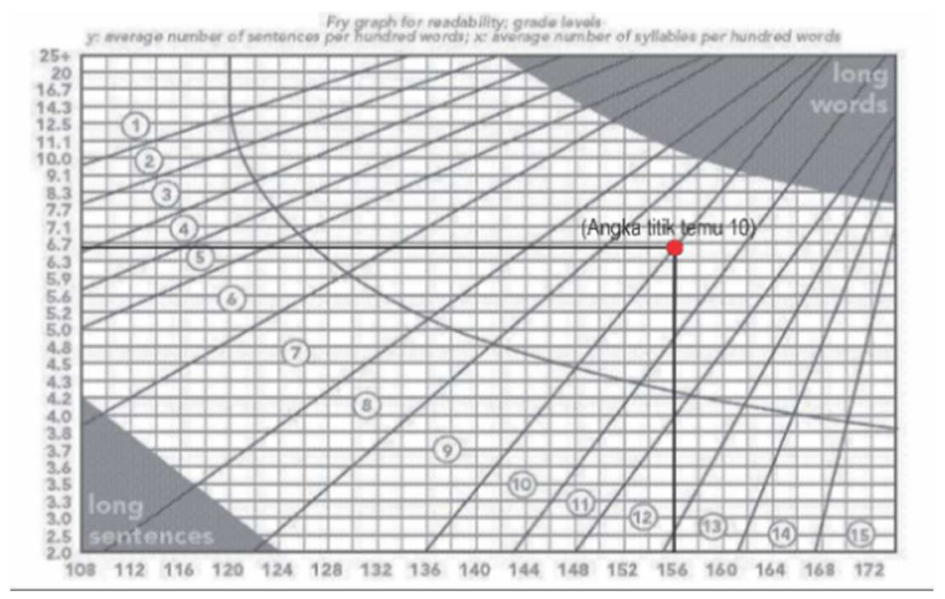

Grafik 1 Fry Kode Teks

Berdasarkan hasil perhitungan, diperoleh tujuh teks yang tidak sesuai dengan penafsiran level $\mathrm{C} 1$. Level $\mathrm{C} 1$ yang dipandang sudah memiliki kemampuan memahami berbagai jenis tulisan yang panjang dan menantang, berjangkauan luas, dan mampu mengenali makna isi teks secara tersurat. Penafsiran kemampuan level tersebut setara dengan tingkatan atau jenjang kelas 10, 11, dan 12. Ketujuh teks yang tidak sesuai tersebut empat teks yang berjudul Pengalaman Berkesan Kali Pertama ke Pulau Dewata, Prosedur Pemasangan Listrik secara Daring (Online), Ki Hajar Dewantara Bapak Pendidikan, Jejaring Sosial bagi Pertumbuhan dan Perkembangan Remaja di Indonesia, dan Kisah Malin Kundang tergolong pada teks setingkat sekolah menengah pertama SMP. Hasil penggabaran grafik Fry kelima teks terbebut berada pada rentang daerah penafsiran, 7, 8, dan 9. Dua teks yang berjudul Seragam Sekolah Perlukah? dan Pemilu Minus Kesukarelaan bergolong sulit karena berada di atas rentang 14 dan 15 yang setara dengan perguruan tinggi atau level $\mathrm{C} 2$.

Berdasarkan hasil perhitungan di atas, dapat disimpulkan bahwa kelima wacana yang sesuai dengan hasil perhitungan Fry dapat pergunakan dalam pembelajaran BIPA level C1 secara langsung. Untuk ketujuh teks lainnya, perlu adanya usaha guru dalam memodifikasi tingkat kesukaran kata, suku kata, dan kerumitan kalimat apabila akan dipergunakan dalam pembelajaran. Wacana yang sesuai dengan grafik Fry tergolong dalam klasifikasi instruksional karena dapat dipergunakan dalam pembelajaran BIPA level C1.

Perhitungan dengan autensitas didasarkan pada keakuratan teks, interaksi sosial, dan kontekstual kebermaknaan teks bagi pembelajar. Autensitas menjadi penting dalam pembelajaran bahasa kedua mengingat latar belakang dan minat pembelajar BIPA akan mempengaruhi pemahaman isi teks xi[10]. Sejalan dengan konsep tersebut, autensitas penelitian ini dibatasi pada dua hal mendasar, yaitu bahasa yang dipelajari dan keaslian sumber bahan ajar atau adanya gubahan dalam wacana oleh penyusun buku teks tersebut. Berdasarkan konsep tersebut, ditentukan klasifikasi autentisitas teks, yaitu autentik tinggi dan autentik simplifikasi [11]. Hal yang sama disampaikan Huang terkait klasifikasi autensitas. Ada tiga klasifikasi, yaitu autentik tinggi, semi-autentik dan artificial [12] [13]. Autentik tinggi berarti sumber bahan ajar akurat dengan aslinya dan tanpa adanya gubahan dari pengajar. Untuk autentik simplifikasi, hal ini berarti bahan ajar mengalami perubahan dan atau sumber teks sudah tidak dapat ditemukan lagi apabila berasal dari situs laman internet. 
Berikut ini hasil analisis teks berdasarkan autensitasnya. Autetifikasi tinggi ditemukan pada teks yang berjudul Ki Hajar Dewantara, Bapak Pendidikan Indonesia; Kisah Malin Kundang; dan Alzheimer. Teks tersebut tidak mengalami perubahan dan dapat dipergunakan dalam pembelajaran. Sembilan teks lainnya memiliki tingkat autentifikasi simplifikasi yang mengalami perubahan agar dapat dipergunakan dalam pembelajaran.

\section{SIMPULAN}

Hasil penelitian ini mengungkapkan dua simpulan yaitu simpulan yang berfokus pada uji keterbacaan wacana buku teks Sahabatku Indonesia terbitan Badan Bahasa level C1 dengan grafik Fry dan kajian autensitas wacana pada buku tersebut. Wacana yang sesuai dengan perhitungan grafik Fry terdapat lima wacana. Kelima wacana tersebut dapat diklasifikasikan sebagai kategori instruksional karena dapat dipergunakan dalam pembelajaran BIPA level C1. Berdasarkan simplifikasi, terdapat tiga teks yang tergolong autentik tinggi dan dapat dipergunakan secara langsung untuk pembelajaran BIPA dan sembilan teks tergolong autentik simplifikasi karena teks sudah mengalami modifikasi agar dapat dipergunakandalam pembelajaran BIPA.

\section{REFERENCES}

[1] M. Mohammadi and H. Abdi, “Textbook Evaluation: A Case Study," Procedia - Soc. Behav. Sci., vol. 98, pp. 1148-1155, 2014.

[2] K. H. Lau, T. Lam, B. H. Kam, M. Nkhoma, J. Richardson, and S. Thomas, "The role of textbook learning resources in e-learning: A taxonomic study," Comput. Educ., vol. 118, pp. 10-24, 2018.

[3] A. Bailin and A. Grafstein, Readability: Text and context. 2016.

[4] B. W. Rishe Purnama Dewi, Septina Krismawati, "Keterbacaan Wacana Buku Teks Ekspresi Diri dan Akademik untuk SMK dengan Grafik Fry, Tes Klos, dan SMOG: Studi Kasus Di SMK N 1 Cilacap dan SMK N 4 Yogyakarta," Widya Dharma J. Kependidikan, vol. 28, no. 2, pp. 245-260, 2016.

[5] R. P. Dewi, “Tingkat Keterbacaan Buku Teks Cakap Berbahasa Indonesia SMP Kelas VII Pada SMP Budya Wacana dan SMP Don Bosco Yogyakarta," Widya Dharma J. Kependidikan, vol. 26, no. 2, pp. 201-223, 2014.

[6] B. Widharyanto and U. S. Dharma, "Autentisitas di dalam pembelajaran bahasa indonesia," no. March 2017, 2018.

[7] S. Crossley, D. Allen, and D. McNamara, "Text readability and intuitive simplification: A comparison of readability formulas," Read. a foreign ..., vol. 23, no. 1, pp. 84-101, 2011.

[8] Lexy J. Moleong, Metodologi penelitian kualitatif. Bandung: Remadja Karya, 2007.

[9] K. Yasa, M. Sutama, and N. Martha, "Kecermatan Formula Flesch, Fog Index , Grafik Fry , Smog , Dan Bi Sebagai Penentu Keefektifan Teks Berbahasa Indonesia," J. Pendidik. Bhs. Indones., vol. 2, no. 1, 2013.

[10] M. Xia, E. Kochmar, and T. Briscoe, "Text Readability Assessment for Second Language Learners," pp. 12-22, 2016.

[11] B. Widharyanto, "Dimensi Autentisitas di dalam Pembelajaran BIPA," 2017.

[12] P. Huang, "Textbook interaction: A study of the language and cultural contextualisation of English learning textbooks," Learn. Cult. Soc. Interact., vol. 21, no. December 2018, pp. 87-99, 2019.

[13] Saddhono, K., \& Erwinsyah, H. Folklore As Local Wisdom for Teaching Materialsin 
BIPA Program (Indonesian for Foreign Speakers). KnE Social Sciences, pp.444-454. 2018. 